\title{
Activation of Akt2 Inhibits anoikis and apoptosis induced by myogenic differentiation
}

\author{
Y Fujio $^{1,4}$, Y Mitsuuchi $^{2}$, JR Testa ${ }^{2}$ and K Walsh ${ }^{\star, 1,3}$ \\ ${ }^{1}$ Division of Cardiovascular Research, St. Elizabeth's Medical Center, Boston, \\ MA 02135, USA \\ 2 Human Genetics Program, Fox Chase Cancer Center, Philadelphia, PA 19111, \\ USA \\ 3 Program in Cell, Molecular, and Developmental Biology, Sackler School of \\ Biomedical Sciences, Tufts University, Boston, MA 02111, USA \\ ${ }^{4}$ Current address: Department of Molecular Medicine, Osaka University Medical \\ School, Suita, Osaka, 565-0871, Japan \\ * Corresponding author: K Walsh, Division of Cardiovascular Research, St. \\ Elizabeth's Medical Center, 736 Cambridge Street, Boston, MA 02135, USA. \\ Tel: (617) 562-7501; Fax: (617) 562-7506; \\ E-mail: kwalsh@opal.tufts.edu or kwalsh@world.std.com
}

Received 17.7.00; revised 14.5.01; accepted 12.6.01

Edited by DR Green

\begin{abstract}
Akt2, a homolog of Akt1, encodes a serine/threonine protein kinase that is amplified in ovarian and pancreatic cancers. The antiapoptotic activities of the Akt1 proto-oncogene product have been well documented, but the role of Akt2 in cellular survival is poorly understood. Here, we demonstrate that Akt2 mRNA, protein and kinase activity are upregulated during serum deprivation-induced $\mathrm{C2}_{2} \mathrm{C} 12$ cell myogenic differentiation, a process that is associated with the acquisition of an apoptosis-resistant phenotype. Transient transfection of plasmids encoding wild-type and constitutively-active Akt2 conferred resistance against apoptosis in differentiating C2C12 cells, while a kinase-negative Akt2 construct did not. Adenovirus-mediated transfer of the constitutively-active Akt2 cDNA also suppressed apoptosis during serum deprivation-induced myogenic differentiation and it protected cells from apoptosis induced by cell detachment. These data indicate that $A k t 2$ functions as an anti-apoptotic gene during cellular differentiation, a property that may contribute to its oncogenicity. Cell Death and Differentiation (2001) 8, $1207-$ 1212.
\end{abstract}

Keywords: apoptosis; signaling; muscle

Abbreviations: PKB, protein kinase B; GM, growth medium; DM, differentiation medium; GFP, green fluorescence protein; DMEM, Dulbecco's modified Eagle medium; IGF, insulin-like growth factor; $\mathrm{HA}$, hemagglutinin; PBS, phosphate-buffered saline; CMV, cytomegalovirus; $\mathrm{MOI}$, multiplicity of infection

\section{Introduction}

Akt2, a serine-threonine protein kinase, is a member of $A k t /$ protein kinase $B(P K B)$ proto-oncogene family. ${ }^{1}$ Both Akt1 and Akt2 function as signal transducers downstream of phosphatidylinositol 3-kinase (PI 3-kinase). ${ }^{2,3}$ Akt1 and Akt2 are encoded by separate genes and are most divergent at their carboxy-terminal regions. ${ }^{3}$ Although it is well established that Akt1 functions as a regulator of glycogen metabolism, growth and survival, ${ }^{4}$ much less is known about the cellular functions of Akt2. Previously, we demonstrated that Akt1 mRNA is expressed ubiquitously, while Akt2 is expressed in a tissue specific manner and is abundant in striated muscles and brown fat. $^{5-7}$ of particular note, the Akt2 gene is amplified in $10-20 \%$ of ovarian and pancreatic cancers, ${ }^{8,9}$ while recurrent amplification of $A k t 1$ has not been observed, suggesting that overexpression of Akt2 contributes to development of some human malignancies. In transformed cells, Akt2 is activated by growth factors, v-ras, and v-src through a PI 3-kinase-mediated mechanism, promoting cell cycle activity and oncogenicity in this context. ${ }^{10,11}$ Deletion of the carboxy-terminal tail in Akt2 abolishes its oncogenic activity. $^{11}$

In contrast to Akt2, it is well recognized that Akt1 inhibits apoptotic cell death in diverse cell types through its ability to phosphorylate and modulate the activities of apoptosisregulatory molecules including Bad, caspase 9, a forkhead transcription factor and $\mathrm{lkB} .^{1}$ Previously, we reported that differentiating myocytes which fail to exit the cell cycle under serum-deprivation conditions will initiate programmed cell death, whereas myocytes that successfully exit the cell cycle will acquire an apoptosis-resistant phenotype and go on to form mature myotubes. ${ }^{12}$ Related studies showed that the myogenic induction of the cell cycle inhibitor p21 and the retinoblastoma protein are essential for successful cell cycle exit, and hence, cellular survival. ${ }^{13-16}$ More recently, we demonstrated that cell cycle exit is essential for efficient Akt1 induction during myogenesis and that the induction of Akt1 is important for myocyte survival. ${ }^{17}$

Antisense RNA to $A k t 2^{9}$ and drugs that interfere with Akt2 signaling ${ }^{18}$ inhibit the tumorigenic phenotype and induce apoptosis in cancer cells that exhibit Akt2 overexpression, consistent with the hypothesis that Akt2 gene amplification promotes cellular survival in tumors. However, nothing is known about the functions of Akt2 in nontumorigenic cells. Here, we report that Akt2 protein and kinase activity are markedly upregulated during serum deprivation-induced myogenic differentiation in $\mathrm{C} 2 \mathrm{C} 12$ cells. Under these conditions, transient transfection of plasmids expressing wild-type or constitutively-active Akt2 promoted myocyte survival. Furthermore, overexpression of Akt2 by adenovirus-mediated gene transfer protected against both differentiation-associated apoptosis and anoikis, cell death that results from the disruption of cell-matrix contacts. $^{19}$ These data provide evidence to suggest that Akt2 induction can promote survival in nontransformed cells in response to diverse cellular stresses. 


\section{Results}

\section{Akt2 protein and kinase activity are upregulated during myogenic differentiation}

Initial experiments examined Akt2 regulation during myogenic differentiation in $\mathrm{C} 2 \mathrm{C} 12$ cells. Like Akt1, ${ }^{17}$ Akt2 protein and histone-kinase activity was expressed at low levels in cycling myoblast cultures in growth medium (GM) (Figure 1A). Two days after cultures were shifted to differentiation media (DM), there was a marked induction of Akt2 protein relative to cdk4, which does not change upon differentiation. ${ }^{20,21}$ Akt1 and Akt2 activity was assessed by determining the histone H2B kinase activity in anti-Akt1 and anti-Akt2 immunoprecipitates from extracts prepared from C2C12 cultures in GM or DM for 2 days (Figure 1B). Corresponding to the induction of protein, kinase activities for both Akt1 and Akt2 were induced to similar levels upon myogenic differentiation. Upregulation of Akt2 transcript was also observed at both day 1 and 2 after C2C12 cells were switched to differentiation media (Figure
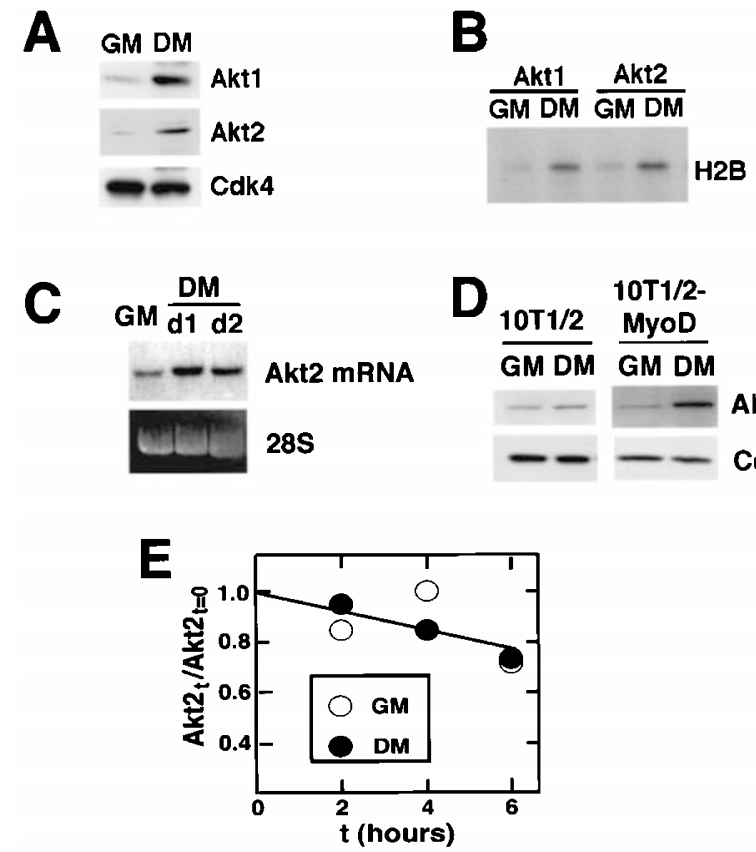

Figure 1 Akt2 upregulation during myogenic differentiation. $\mathrm{C} 2 \mathrm{C} 12$ cells were cultured in growth medium (GM) (A, B, C and E). To induce differentiation, the medium was changed to differentiation medium (DM) for 2 days. (A) Cell lysates were immunoblotted with anti-Akt1, anti-Akt2, or antiCdk4 antibody. (B) Cell lysates were immunoprecipitated with anti-Akt1 or anti-Akt2 antibody, and kinase activities in the immunoprecipitate were measured using histone $\mathrm{H} 2 \mathrm{~B}$ as a substrate. (C) Total RNA was prepared from $\mathrm{C} 2 \mathrm{C} 12$ cells cultured in growth medium (GM) or differentiation medium (DM) for 1 day (1d) or 2 days (2d). Total RNA $(25 \mu \mathrm{g})$ was analyzed by Northern blotting using the Akt2 probe. Ribosomal 28S RNA indicates equal loading. (D) $10 \mathrm{~T} 1 / 2$ cells and $10 \mathrm{~T} 1 / 2$ cells expressing MyoD were cultured in growth medium (GM) or differentiation medium (DM) for 2 days. Cell lysates were prepared and immunoblotted with anti-Akt2 or anti-Cdk4 antibody. (E) C2C12 cells were cultured in GM or DM for 2 days and exposed to cyclohexamide to inhibit protein synthesis. At 2, 4 and $6 \mathrm{~h}$ lysates were prepared from parallel cultures and immunoblotted for Akt2 and cdc2 expression. Cdc2 levels do no change upon myogenic differentiation. ${ }^{30}$ The ratio of Akt2 to cdc2 signal in the absence of cyclohexamide $(T=0)$ is assigned a value of 1.0. Data from two independent experiments are shown
1C). Densiometric scanning indicated a fourfold upregulation by 1 day.

To examine myogenic Akt2 protein induction in greater detail, we analyzed its expression in a 10T1/2 cell line that is stably transformed with MyoD ${ }^{15}$. These MyoD-transformed cells differ from the parental 10T1/2 line in that they form multinucleated myotubes when exposed to differentiation medium. Differentiating 10T1/2-MyoD cells upregulated Akt2 protein, whereas Akt2 was induced when parental 10T1/2 cells were exposed to differentiation media (Figure 1D). Thus, Akt2 induction requires myogenic bHLH factorinduced commitment to differentiation.

Finally, Akt2 protein half-life was examined in $\mathrm{C} 2 \mathrm{C} 12$ cells cultured in the presence of cyclohexamide in growth medium or differentiation medium (Figure 1E). In contrast to Akt1, ${ }^{17}$ no changes in Akt2 protein stability were detected. Collectively, these data show that the induction of Akt2 protein during myogenesis is due to changes in the level of its transcript.

Transient transfection of Akt2 promotes cell survival in C2C12 cell: As reported previously, ${ }^{12,14,17}$ a portion of $\mathrm{C} 2 \mathrm{C} 12$ cells will undergo apoptotic cell death prior to cell cycle withdrawal when exposed to DM. To analyze the effects of Akt2 on cell survival, plasmid vector alone (pcDNA3) or vector expressing wild-type and mutated forms of Akt2 were co-transfected with a GFP expression vector to mark transfected cells. After cells were cultured in GM overnight, the medium was changed to serum-free DMEM. The fraction of GFP-positive cells with pyknotic nuclei, a feature of apoptosis, was determined at $24 \mathrm{~h}$ (Figure 2A). As shown in Figure 2B, transfection with wild-type Akt2 or myrAkt2 resulted in a significantly lower frequency of GFP-positive cells with pyknotic nuclei compared with vector alone. Furthermore, a vector expressing a kinase-negative form of Akt2 (knAkt2), with a mutation in the active site at amino acid 299 which converts a glutamate residue to lysine, displayed no protective effect during serum deprivation-induced myogenic differentiation.

Adenoviral transfer of constitutively-active Akt2 confers resistance to anoikis and apoptosis induced by myogenic differentiation: To further analyze the anti-apoptotic properties of Akt2, replication-defective adenoviral vectors expressing HA-tagged kinase-negative (Adeno-knAkt2) and constitutively-active Akt2 (Adeno-myrAkt2) were constructed (Figure 3A). C2C12 cells infected with Adeno-knAkt2 or Adeno-myrAkt2 expressed comparable levels of transgene as determined by immunoblot analysis with anti-HA antibody (Figure 3B). No immunoblot signal was detected in $\mathrm{C} 2 \mathrm{C} 12$ cells infected with a control adenovirus vector that expresses $\beta$-galactosidase (Adeno- $\beta$ gal) from the CMV promoter. The expression levels of knAkt2 and myrAkt2 adenovirus transgenes relative to endogenous Akt2 protein is shown in Figure 3C.

To analyze the anti-apoptotic effects of Akt2 during mitogen deprivation-induced myogenesis, myoblast cultures were mock-infected or infected with Adeno- $\beta$ gal, AdenoknAkt2, or Adeno-myrAkt2 and then induced to differentiate in serum-free DMEM. Flow cytometric analysis revealed a large fraction of cells containing hypodiploid DNA, an indicator of apoptotic cell death, in the mock, Adeno- $\beta$ gal 

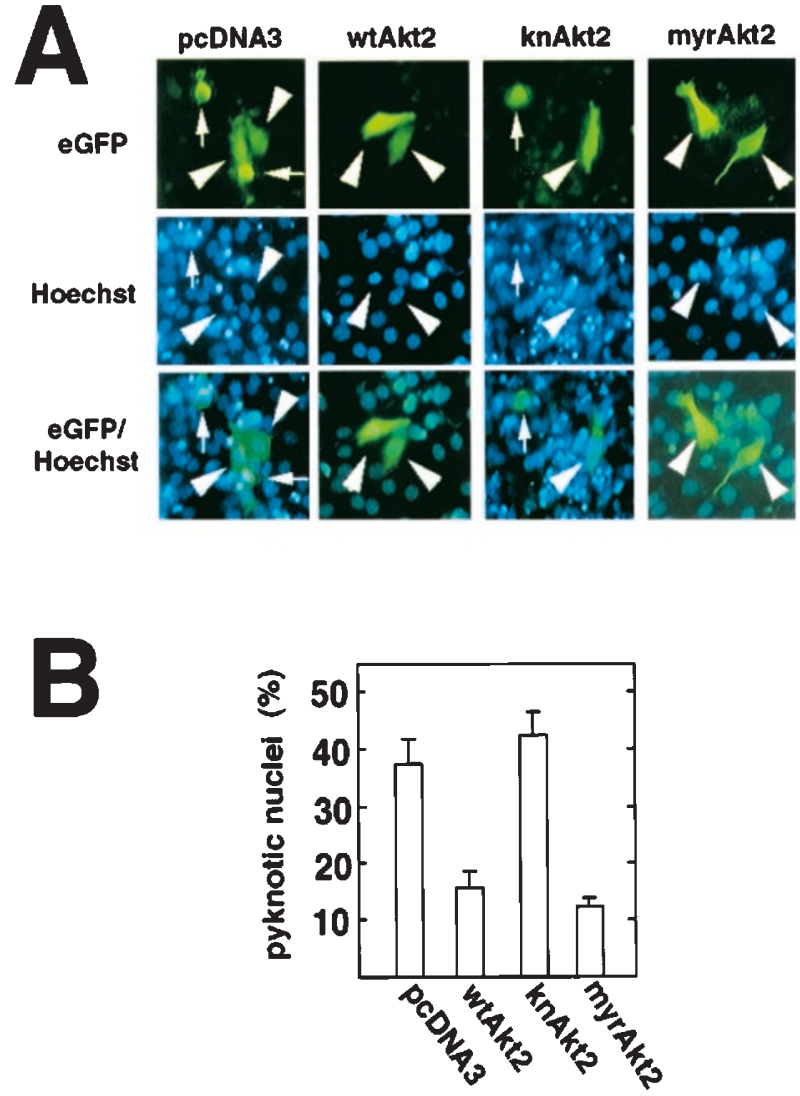

Figure 2 Effect of Akt2 on myocyte apoptosis during serum deprivationinduced differentiation. $\mathrm{C} 2 \mathrm{C} 12$ cells were co-transfected with a plasmid expressing green fluorescent protein (GFP), as a transfection marker, and plasmids encoding wild-type Akt2 (wtAkt2), kinase-negative Akt2 (knAkt2), or constitutively-active Akt2 (myrAkt2). Control cultures were transfected with the GFP-encoding plasmid and empty vector (pcDNA3). Apoptosis was assessed following incubation in serum-free medium for 24 hours. Cells were fixed and stained with Hoechst 33342 and fluorescence was observed in microscopic fields. (A) Representative photomicrographs showing myocytes co-transfected with the GFP expression vector and empty vector (pcDNA3) or expression vectors encoding knAkt2 or myrAkt2. Note that myrAkt2 or wtAkt2 co-transfected cells display normal nuclei (arrowheads), while some cells cotransfected with knAkt2 or empty vector become rounded and display pyknotic nuclei (arrows). (B) Quantitation of GFP-positive cells that display condensed nuclei. Data were shown as mean $+/-$ S.E.M. (wtAkt2 and myrAkt2 are $P<0.05$ relative to pcDNA3 condition)

and Adeno-knAkt2 experimental conditions (Figure 4). In contrast cells infected with Adeno-myrAkt2 displayed a reduced fraction of hypodiploid DNA indicating a reduction in apoptosis.

Previously, it has been reported that Akt1 protects against anoikis in endothelial and epithelial cells. ${ }^{20,22}$ To test whether Akt2 has a similar function in muscle cells, that also undergo anoikis, ${ }^{23}$ myoblast cultures were transfected with Adeno$\beta$ gal or Adeno-myrAkt2 and cultured in BSA-coated bacterial plates to prevent adhesion. After $24 \mathrm{~h}$ in suspension culture, DNA content was analyzed to assess apoptosis. As shown in Figure 5, a large fraction of the total DNA was hypodiploid in the mock- and Adeno- $\beta$ gal-transduced cultures. In contrast, infection with Adeno-myrAkt markedly reduced the fraction of the DNA in the sub-G1 population, indicating
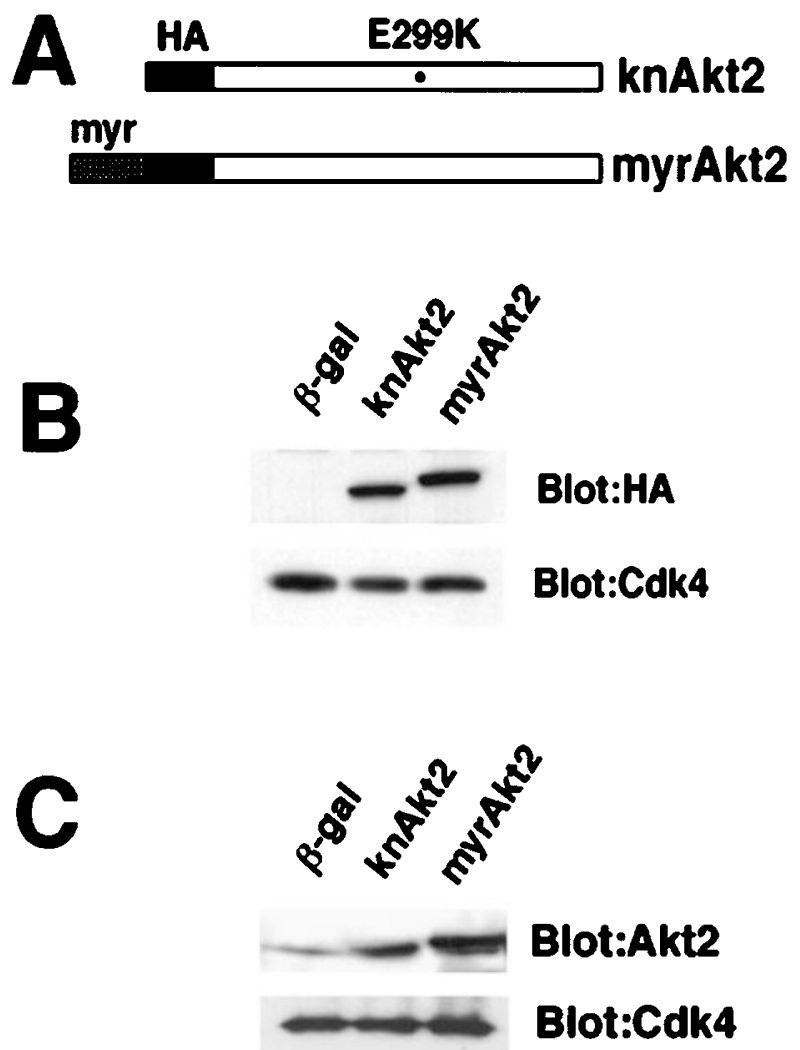

Figure 3 Structures and expression of Akt2 cDNAs from adenoviral vectors. (A) The knAkt2 construct has glutamate substituted for lysine at amino acid position 299. The myrAkt2 construct has the wild-type-Akt2 protein coding sequence fused to the c-src myristoylation sequence. Both proteins are fused to the HA tag for immunoblot analysis. (B and $\mathbf{C}$ ) $\mathrm{C} 2 \mathrm{C} 12$ myoblasts were infected with Adeno- $\beta$ gal, Adeno-knAkt2 or Adeno-myrAkt2 for $15 \mathrm{~h}$. Cell lysates were prepared and immunoblotted with anti-HA antibody (B) or antiAkt2 antibody (C). Immunoblots for Cdk4 indicate equal loading

that constitutive activation of Akt2 is sufficient to promote survival in the absence of cellular adhesion. Infection with Adeno-knAkt2 had no detectable effect on the fraction of cells undergoing anoikis relative to mock- and Adeno- $\beta$ galtransduced cultures (data not shown).

\section{Discussion}

In this study we demonstrate that Akt2 can promote survival under conditions where non-tumorigenic cells are deprived of mitogens or proper matrix associations. Transient transfection of plasmids encoding either wild-type or constitutively-active Akt2 was found to inhibit apoptosis in $\mathrm{C} 2 \mathrm{C} 12$ myocytes that are induced to differentiate under low serum culture conditions. These data were corroborated by the observation that adenovirus-mediated expression of constitutively-active Akt2 also promotes survival in differentiating myocyte cultures. Constitutively-active Akt2 also inhibits anoikis, apoptotic cell death that occurs in non-transformed cells when their substratum-cell adhesions are disrupted. ${ }^{19,23}$ Collectively, these data suggest that Akt2 can modulate both growth factor- and matrix attachment-mediated survival signals. 
FCS

$(+)$

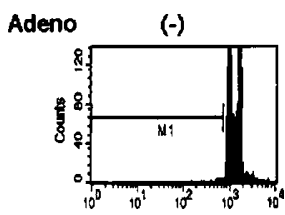

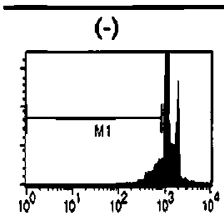

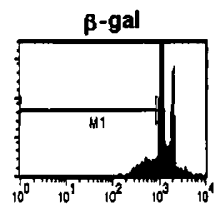

$(-)$

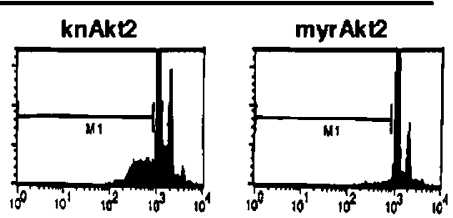

Figure 4 Adenovirus-mediated transfer of constitutively-active Akt promotes cellular survival during mitogen deprivation-induced myogenesis. Representative experiment showing adenoviral transfer of myrAkt2 confers resistance to apoptosis induced by serum-deprivation. C2C12 cells were mock-infected or infected with Adeno- $\beta$ gal, Adeno-knAkt2 or Adeno-myrAkt2 in GM overnight. The media was then changed to serum-free DMEM 24 hours. Alternatively, a mock-infected culture was maintained in GM. Cells were harvested and stained with propidium iodide, and DNA content was analyzed with a flow cytometer. M1 indicates region of hypodiploid DNA
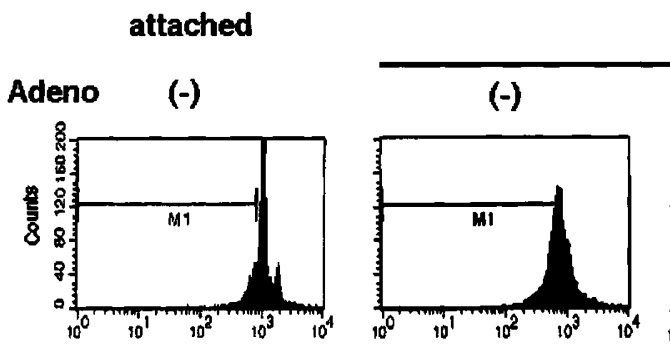

suspension

Figure 5 Adenovirus-mediated transfer of constitutively-active Akt2 inhibits anoikis in C2C12 cells. Representative experiment showing constitutively-active Akt2 protects against cell death induced by cell detachment. Cells were mock-infected or infected with Adeno- $\beta$ gal or Adeno-myrAkt2 overnight. Cells were then harvested with EDTA and incubated in suspension culture in GM for $24 \mathrm{~h}$ prior to DNA content analysis. Parallel mock-infected cultures were maintained in monolayer conditions (attached) for comparison. M1 indicates region of hypodiploid DNA

This study also demonstrates that both Akt2 protein and protein kinase activity are upregulated during myogenic differentiation in $\mathrm{C} 2 \mathrm{C} 12$ cells and in $10 \mathrm{~T} 1 / 2$ cells that are transformed with MyoD. These data are consistent with the observation that Akt2 mRNA is induced in myogenic cell lines upon differentiation. ${ }^{5,6}$ At the levels of activity and protein, the upregulation of Akt2 is similar to that of Akt1 (see Figure 1). However, the mechanism of the upregulation is different for Akt1 and Akt2. Myogenic induction of Akt2 is mediated by an increase in transcript, ${ }^{5,6}$ while induction of Akt1 occurs through stabilization of the protein with no accompanying change in mRNA levels. ${ }^{17}$ Data from the current study also suggest that Akt2 induction may function to protect differentiating myocytes from apoptosis. Overexpression of wild-type Akt2 suppressed apoptosis to a similar degree as constitutively-active Akt2. Presumably, the wild-type transgene is activated by insulin-like growth factor-II (IGF-II) which is produced by differentiating myocytes. ${ }^{24-26}$ In this regard, it has been shown that IGF-II functions as an autocrine survival factor during myoblast differentiation. ${ }^{27,28}$

Finally, the anti-apoptotic activities of Akt2 described here may contribute to its role in malignancy and explain why Akt2 gene amplification is observed in pancreatic and ovarian cancers. ${ }^{8,9}$ It is well recognized that anti-apoptotic genes contribute to malignancy. In particular, anoikis prevents detached cells from colonizing in inappropriate locations, thereby protecting against metastasis. ${ }^{29}$ Thus, our observation that enhanced Akt2 signaling can confer resistance to anoikis suggests that the amplification and/or overexpression of this factor may contribute to tumor formation and invasiveness. Therefore, as an anti-apoptotic signal transducer, Akt2 could have a role in controlling cell survival during normal differentiation as well as contribute to the development of human malignancies.

\section{Materials and Methods}

\section{Cell Culture}

$\mathrm{C} 2 \mathrm{C} 12$ cells were cultured as described previously. ${ }^{13}$ Cells were maintained in growth medium (GM) which consists of Dulbecco's modified Eagle medium (DMEM) containing 20\% fetal calf serum. Differentiation was induced by switching GM to differentiation medium (DM) which consists of serum-free DMEM or DMEM plus $2 \%$ heatinactivated horse serum. Suspension cultures were obtained as described in. ${ }^{20}$ Briefly, cells were washed with phosphate-buffered saline (PBS) twice and harvested with PBS containing $0.5 \%$ EDTA. Cells were collected by centrifugation, resuspended in DMEM, and cultured on bacterial culture dishes precoated with $20 \mathrm{mg} / \mathrm{ml}$ bovine serum albumin (BSA). 10T1/2 cells and MyoD-transformed 10T1/2 cells were cultured as described previously. ${ }^{15}$ Cells were maintained in GM, and switched to DM for 2 days.

\section{Northern blot analyses}

Northern blotting was performed as described previously. ${ }^{17}$ Briefly, total RNA was prepared with the acid guanidium thiocyanate-phenolchloroform method. ${ }^{29}$ Total RNA $(25 \mu \mathrm{g})$ was separated in formaldehyde gel and transferred to a Hybond $\mathrm{N}$ membrane. The cDNA 
fragment corresponding to the pleckstrin homology domain of mouse Akt was used as a probe. After hybridization and washing, membranes were exposed to X-ray film overnight.

\section{Immunoblot analyses}

Immunoblot analyses were performed as described in. ${ }^{17}$ In brief, cells were washed twice in PBS on ice and extracted with cell lysis buffer (1\% Nonidet P-40, 10\% glycerol, $137 \mathrm{mM} \mathrm{NaCl}, 20 \mathrm{mM}$ Tris- $\mathrm{HCl}$ [pH 7.4], $20 \mathrm{mM} \mathrm{NaF}, 1 \mathrm{mM}$ phenylmethyl-sulfonyl fluoride) for $15 \mathrm{~min}$. at $4^{\circ} \mathrm{C}$, followed by centrifugation at 15000 r.p.m. for $15 \mathrm{~min}$. Twenty micrograms of protein were separated on SDS polyacrylamide gel. Proteins were transferred onto a polyvinylidine difluoride membrane (Millipore). After blocking with $5 \%$ nonfat milk protein, the membranes were incubated with anti-Akt1 (Santa Cruz), anti-Akt2 (Upstate), anti-cdc2 (Santa Cruz), anti-hemagglutinin (HA) (Boehringer), or anti-Cdk4 antibody (Santa Cruz). Blots were incubated with the secondary antibody conjugated with horse-radish peroxidase (donkey anti-goat (Santa Cruz), donkey anti-rabbit (Amersham), or rabbit anti-sheep (Pierce). An enhanced chemiluminescence protocol was used for detection according to the directions of the manufacturer (Amersham Life Science).

\section{Akt2 half-life determinations}

Cultures of $\mathrm{C} 2 \mathrm{C} 12$ cells were incubated in growth medium or differentiation media for two days. Parallel cultures were then exposed to $35 \mu \mathrm{M}$ cyclohexamide and lysates were prepared after 2, 4 and $6 \mathrm{~h}$. Western immunoblots were performed to determine Akt2 levels relative to the level of cdc2, which remains constant under these conditions. ${ }^{30}$

\section{Akt protein kinase assays}

Cell lysates were prepared as described above. Cell lysates $(200 \mu \mathrm{g}$ per assay) were immunoprecipitated with anti-Akt1 or Akt2 antibody using protein $\mathrm{G}$ agarose (Boehringer). After two washes with lysis buffer, one wash with $\mathrm{H}_{2} \mathrm{O}$, and two washes with kinase buffer $(20 \mathrm{mM}$ HEPES [pH 7.2], $10 \mathrm{mM} \mathrm{MgCl} 2,10 \mathrm{mM} \mathrm{MnCl}_{2}$ ), kinase assays were performed as described previously ${ }^{17}$ using histone $\mathrm{H} 2 \mathrm{~B}$ as a substrate.

\section{Transient transfection and cell viability analysis}

Plasmids included vector (pcDNA3) with no insert or encoding wildtype Akt2, kinase-negative Akt2 (knAkt2), or constitutively-active Akt2 (myrAkt2) expressed from the cytomegalovirus (CMV) promoter/ enhancer. ${ }^{31}$ Plasmids were cotransfected with an expression vector encoding enhanced green fluorescent protein (GFP) (Clontech) with LipofectAmine as described in. ${ }^{17}$ After $18 \mathrm{~h}$ incubation in GM, apoptosis was induced by changing GM to serum-free medium. After incubated for $24 \mathrm{~h}$, cells were fixed with $3.7 \%$ formaldehyde in PBS and stained with Hoechst 33342. GFP-positive cells with pyknotic nuclei were determined by visual examination.

\section{Adenovirus construction and transfection}

Replication-defective adenovirus vectors were constructed according to. ${ }^{32}$ Briefly, knAkt2 or myrAkt2 cDNAs, fused at their N-terminus to the hemagglutinin epitope $(\mathrm{HA})$, were inserted into the multicloning site of pACCMVpLpA. The resulting plasmids were cotransfected with pJM17 into 293 cells to allow for homologous recombination. An adenovirus construct expressing $\beta$-galactosidase from the CMV promoter/enhancer was used as a control. ${ }^{33}$ All constructs were amplified in 293 cells and purified by ultracentrifugation in the presence of $\mathrm{CsCl}$. For transfection, $\mathrm{C} 2 \mathrm{C} 12$ cells were incubated with adenovirus vectors in $\mathrm{GM}$ for $15 \mathrm{~h}$. $\mathrm{C} 2 \mathrm{C} 12$ cells were infected at a multiplicity of infection (MOI) of 250 , which leads to $>95 \%$ efficiency of transgene transduction. ${ }^{17}$

\section{Flow cytometry}

DNA content of adenovirus construct-infected or mock-infected cells was measured with a FACScan flow cytometer (Becton Dickson) as described in. ${ }^{14}$

\section{Acknowledgements}

This work was supported by NIH grants HD-23681, AR-40197 and AG15052 to $\mathrm{K}$ Walsh and $\mathrm{NCl}$ grants $\mathrm{CA}-77429$ and CA-06927 to JR Testa.

\section{References}

1. Datta SR, Brunet A and Greenberg ME (1999) Cellular survival: a play in three Akts. Genes Dev. 13: 2905-2927

2. Franke TF, Yang S-I, Chan TO, Datta K, Kazlauskas A, Morrison DK, Kaplan DR and Tsichlis PN (1995) The protein kinase encoded by the Aktproto-oncogene is a target of the PDGF-activated phophatidylinositol 3-kinase. Cell. 81: 727-736

3. Testa JR and Bellacosa A (1997) Membrane translocation and activation of the Akt kinase in growth factor-stimulated hematopoietic cells. Leukemia Res. 21 : 1027-1031

4. Coffer PJ, Jin J and Woodgett JR (1998) Protein kinase B (c-Akt): a multifunctional mediator of phosphatidylinositol 3-kinase activation. Biochem. J. 335: $1-13$

5. Altomare DA, Guo K, Cheng JQ, Sonoda G, Walsh K and Testa JR (1995) Cloning, chromosomal localization and expression analysis of the mouse Akt2 oncogene. Oncogene. 11: 1055-1060

6. Altomare DA, Lyons GE, MitsuuchiY, Cheng JQ and Testa JR (1998) Akt2mRNA is highly expressed in embryonic brown fat and AKT2 kinase is activated by insulin. Oncogene. 16: 2407-2411

7. Calera MR and Pilch PF (1998) Induction of Akt-2 correlates with differentiation in Sol8 muscle cells. Biochem. Biophys. Res. Commun. 251: 835-841

8. Cheng JQ, Godwin AK, Bellacosa A, Taguchi T, Franke TF, Hamilton TC, Tsichlis PN and Testa JR (1992) AKT2, a putative oncogene encoding a member of a subfamily of protein-serine/threonine kinases, is amplified in human ovarian carcinomas. Proc. Natl. Acad. Sci. USA. 89: 9267-9271

9. Cheng JQ, Ruggeri B, Klein WM, Sonoda G, Altomare DA, Watson DK and Testa JR (1996) Amplification of AKT2 in human pancreatic cells and inhibition of AKT2 expression and tumorigenicity by antisense RNA. Proc. Natl. Acad. Sci. USA. 93: $3636-3641$

10. Liu A, Testa JR, Hamilton TC, Jove R, Nicosia SV and Cheng JQ (1998) AKT2, a member of protein kinase B family, is activated by growth factors, v-Ha-ras, and vsrc through phosphatidylinositol 3-kinase in human ovarian epithelial cancer cells. Cancer Res. 58: 2973-2977

11. Cheng JQ, Altomare DA, Klein MA, Lee WC, Kruh GD, Lissy NA and Testa JR (1997) Transforming activity and mitosis-related expression of the AKT2 oncogene: evidence suggesting a link between cell cycle regulation and oncogenesis. Oncogene. 14: 2793-2801

12. Wang J and Walsh K (1996) Resistance to apoptosis conferred by Cdk inhibitors during myocyte differentiation. Science. 273: 359-361

13. Andrés V and Walsh K (1996) Myogenin expression, cell cycle withdrawal and phenotypic differentiation are temporally separable events that precede cell fusion upon myogenesis. J. Cell Biol. 132: 657-666

14. Wang J, Guo K, Wills KN and Walsh K (1997) Rb functions to inhibit apoptosis during myocyte differentiation. Cancer Res. 57: 351-354 
15. Guo K, Wang J, Andrés V, Smith RC and Walsh K (1995) MyoD-induced expression of p21 inhibits cyclin-dependent kinase activity upon myocyte terminal differentiation. Mol. Cell Biol. 15: 3823-3829

16. Zacksenhaus E, Jiang Z, Chung D, Marth JD, Phillips RA and Gallie BL (1996) $\mathrm{pRb}$ controls proliferation, differentiation, and death of skeletal muscle cells and other lineages during embryogenesis. Genes Dev. 10: 3051-3064

17. Fujio Y, Guo K, Mano T, Mitsuuchi Y, Testa JR and Walsh K (1999) Cell cycle withdrawal promotes myogenic induction of Akt, a positive modulator of myocyte survival. Mol. Cell Biol. 19: 5073-5082

18. Jiang K, Coppola D, Crespo NC, Nicosia SV, Hamilton AD, Sebti SM and Cheng JQ (2000) The phosphoinositide 3-OH kinase/AKT2 pathway as a critical target for farnesyltransferase inhibitor-induced apoptosis. Mol. Cell Biol. 20: 139-148

19. Frisch SM and Francis $H$ (1994) Disruption of epithelial cell-matrix interactions induces apoptosis. J. Cell Biol. 124: 619-626

20. Fujio $Y$ and Walsh $K$ (1999) Akt mediates cytoprotection of endothelial cells by vascular endothelial growth factor in an anchorage-dependent manner. J. Biol. Chem. 274: 16349-16354

21. Wang J and Walsh K (1996) Inhibition of retinoblastoma protein phosphorylation by myogenesis-induced changes in the subunit composition of the cyclindependent kinase 4 complex. Cell Growth Diff. 7: 1471-1478

22. Khwaja A, Rodriguez-Viciana P, Wennstrom S, Warne PH and Downward $J$ (1997) Matrix adhesion and Ras transformation both activate a phosphoinositide 3-OH kinase and protein kinase B/Akt cellular survival pathway. EMBO J. 16 2783-2793

23. Vachon PH, Loechel F, Xu H, Wewer UM and Engvall E (1996) Merosin and laminin in myogenesis; specific requirement for merosin in myotube stability and survival. J. Cell Biol. 134: 1483-1497

24. Rosen KM, Wentworth BM, Rosenthal N and Villa-Komaroff L (1993) Specific temporally regulated expression of the insulin-like growth factor II gene during muscle cell differentiation. Endocrinology. 133: 474-481
25. Florini JR, Ewton EZ and Magri KA (1991) Hormones, growth factors and myogenic differentiation. Annu. Rev. Physiol. 53: 201-216

26. Tollefsen SE, Sadow JL and Rotwein P (1989) Coordinate expression of insulinlike growth factor II and its receptor during muscle differentiation. Proc. Natl. Acad. Sci. USA. 86: 1543-1547

27. Steele PM, Chesebro JH, Stanton AW, Holmes DR, Dewanjee MK, Badimon L and Fuster V (1985) Balloon Angioplasty; natural history of the pathophysiological response to injury in a pig model. Circ. Res. 57: 105-112

28. Stewart CEH and Rotwein $P$ (1996) Insulin-like growth factor-II is an autocrine survival factor for differentiating myoblasts. J. Biol. Chem. 271: 11330-11338

29. Chomczynski Pand Sacchi N (1987) Single-step method of RNA isolation by acid guanidinium Thiocyanate-Phenol-Chloroform Extraction. Anal. Biochem. 162: $156-159$

30. Song A, Wang Q, Goeble MG and Harrington MA (1998) Phosphorylation of nuclear MyoD is required for its rapid degradation. Mol. Cell Biol. 18: 4994-4999

31. Mitsuuchi Y, Johnson SW, Moonblatt S and Testa JR (1998) Translocation and activation of AKT2 in response to stimulation by insulin. J. Cell Biochem. 70: 433-441

32. Becker TC, Noel RJ, Coats WS, Gomez-Foix AM, Alam T, Gerard RD and Newgard CB (1994) Use of recombinant adenovirus for metabolic engineering of mammalian cells. In Methods in Cell Biology. (New York, NY: Academic Press) pp. $161-189$

33. Smith RC, Branellec D, Gorski DH, Guo K, Perlman H, Dedieu J-F, Pastore C, Mahfoudi A, Denèfle P, Isner JM and Walsh K (1997) p21 ${ }^{\mathrm{CIP} 1}$-mediated inhibition of cell proliferation by overexpression of the gax homeodomain gene. Genes Dev. 11: 1674-1689 